\title{
Wavelength dependence of noise figure in InGaAs/InGaAsP multiple-quantum-well laser amplifier
}

Jepsen, Kim Stokholm; Mikkelsen, Benny; Povlsen, Jørn Hedegaard; Yamaguchi, M.; Stubkjær, Kristian

Published in:

I E E E Photonics Technology Letters

Link to article, DOI:

10.1109/68.141964

Publication date:

1992

Document Version

Publisher's PDF, also known as Version of record

Link back to DTU Orbit

Citation (APA):

Jepsen, K. S., Mikkelsen, B., Povlsen, J. H., Yamaguchi, M., \& Stubkjær, K. (1992). Wavelength dependence of noise figure in InGaAs/InGaAsP multiple-quantum-well laser amplifier. I E E E Photonics Technology Letters, 4(6), 550-553. https://doi.org/10.1109/68.141964

\section{General rights}

Copyright and moral rights for the publications made accessible in the public portal are retained by the authors and/or other copyright owners and it is a condition of accessing publications that users recognise and abide by the legal requirements associated with these rights.

- Users may download and print one copy of any publication from the public portal for the purpose of private study or research.

- You may not further distribute the material or use it for any profit-making activity or commercial gain

- You may freely distribute the URL identifying the publication in the public portal 
Interdisciplinary Laser Sci. Conf. (ILS-VI), Minneapolis, Sept. 1990 (unpublished), paper B3-1.

[4] R. Scheps, J. F. Myers. H. B. Serreze, A. Rosenberg, R. C. Morris, and $\mathrm{M}$. Long, "Diode-pumped Cr:LiSrAlF 6 laser," Opt. Lett., vol. 16 , pp. 820-822, 1991.

[5] Q. Zhang, G. J. Dixon, B. H. T. Chai, and P. N. Kean, "Electronically tuned diode-laser-pumped Cr:LiSrAlF 6 laser," Opt. Lett., vol. 17, pp. 43-45, 1992.

[6] H. B. Serreze, Y. C. Chen, and R. G. Waters, "High power, very low threshold, GaInP/AIGalnP visible laser diodes," Appl. Phys. Lett., vol. 58, pp. 2464-2466, 1991.

[7] S. A. Payne, L. L. Chase, H. W. Newkirk, L. K. Smith, and W. F. Krupke, "LiCaAlF $6: \mathrm{Cr}^{3+}: \mathrm{A}$ promising new solid-state laser material," IEEE J. Quantum Electron., vol. 24, pp. 2243-2252, 1988.

[8] S. A. Payne, L. L. Chase, L. K. Smith, W. L. Kway, and H. W. Newkirk, "Laser performance of LiSrAlF $6 \mathrm{Cr}^{3+}$, , J. Appl. Phys., vol. 66, pp. 1051-1056, 1989.

[9] L. K. Smith, S. A. Payne, W. L. Kway, L. L. Chase, and B. H. T.
Chai, "Investigation of the laser properties of $\mathrm{Cr}^{3+}: \mathrm{LiSrGaF}_{6}$," IEEE J. Quantum Electron., 1992.

[10] D. L. Sipes, "A highly efficient Nd:YAG laser end pumped by a semiconductor laser array," Appl. Phys. Lett., vol. 47, pp. 74-76, 1985.

[11] R. Scheps, "Cr-doped solid state lasers pumped by visible laser diodes," J. Opt. Mat., vol. 1, pp. 1-9, 1992.

[12] D. F. Welch, T. Wang, and D. Scifres, "Characteristics of visible laser diodes for solid state laser pumps," presented at the Seventh Interdisciplinary Laser Sci. Conf. (ILS-VII), Monterey, CA, Sept. 1991 (unpublished).

[13] D. Findlay and R. A. Clay, "The measurement of internal losses in 4-level lasers," Phys. Lett., vol. 20, pp. 277-278, 1966.

[14] R. Scheps, J. F. Myers, and S. A. Payne, "CW and Q-switched operation of a low threshold $\mathrm{Cr}^{+3}: \mathrm{LiCaAlF}_{6}$ laser," IEEE Photon. Technol. Lett., vol. 2, pp. 626-628, 1990.

[15] K. Kubodera, K. Otsuka, and S. Miyazawa, "Stable $\mathrm{LiNdP}_{4} \mathrm{O}_{12}$ miniature laser," Appl. Opt., vol. 18, pp. 884-890, 1979.

\title{
Wavelength Dependence of Noise Figure in InGaAs/InGaAsP Multiple-Quantum-Well Laser Amplifier
}

\author{
K. S. Jepsen, B. Mikkelsen, J. H. Povlsen, M. Yamaguchi, and K. E. Stubkjaer
}

\begin{abstract}
Theoretical and experimental results are presented for the wavelength dependence of the noise figure and the single-pass gain in multiquantum well amplifiers. The theoretical model accounts for both conduction band/heavy-hole band and conduction band/light-hole band transitions. The calculations are in good agreement with the experimental results, which indicate that the noise figure has some dependence on the wavelength. A minimum TWA noise figure of $3.9 \mathrm{~dB}$ has been measured at $1550 \mathrm{~nm}$ for a single-pass gain of $22 \mathrm{~dB}$.
\end{abstract}

\section{INTRODUCTION}

S EMICONDUCTOR optical amplifiers (SOA) based on quantum-wells (QW) have recently been attracting attention, as they offer noise and saturation properties superior to those of conventional bulk SOA's [1], [2]. Previously, a noise figure of $4.6 \mathrm{~dB}$ at a gain of $20 \mathrm{~dB}$ has been reported for a multiquantum-well (MQW) GaAlAs amplifier [1]. In this letter, measurements of the noise figure for a traveling-

Manuscript received December 17, 1991; revised March 5, 1992.

K. S. Jepsen, B. Mikkelsen, J. H. Povlsen, and K. E. Stubkjaer are with the Center for Broadband Telecommunications, Electromagnetics Institute, Technical University of Denmark, DK-2800 Lyngby, Denmark. M. Yamaguchi is with NEC Corporation, Kanagawa 213, Japan. IEEE Log Number 9200240 wave amplifier (TWA) at three different wavelengths are presented along with a detailed theoretical assessment of the wavelength dependency of the noise figure. For the 4-well MQW TWA considered here, a noise figure of $3.9 \mathrm{~dB}$ at $1550 \mathrm{~nm}$ for a single-pass gain of $22 \mathrm{~dB}$ is reported.

\section{THEORY}

In an optical amplifier the noise is due to spontaneous emission. By considering the differential equations for the average number of photons and the variance of the number of photons passing through a cross-section of the amplifier in a given period of time, the noise figure for a TWA can be evaluated in analogy with [3]:

$$
F_{\mathrm{TWA}}=2 \frac{\Gamma \alpha_{e}}{\Gamma g-\alpha_{\text {loss }}} \equiv 2 \gamma_{\mathrm{sp}} \frac{g}{\left(g-\left(\alpha_{a}-\alpha_{b}\right)\right)-\alpha_{b} / \Gamma}
$$

where $\Gamma$ is the confinement factor, $\alpha_{e}$ the rate of stimulated emission of photons into the considered mode divided by the group velocity of light, $g$ the gain, and $\gamma_{\mathrm{sp}} \equiv \alpha_{e} / g$ the population inversion parameter. The internal loss is given by $\alpha_{\text {loss }}=\Gamma \alpha_{a}+(1-\Gamma) \alpha_{b}$ where $\alpha_{a}$ is the loss in the active layers and $\alpha_{b}$ the loss in the barrier and cladding layers. 
To calculate the gain in (1) the $\boldsymbol{k} \cdot \boldsymbol{p}$ approximation [4] has been used, taking into account both the conduction band/heavy-hole band $(c-h h)$ and the conduction band/light-hole band $(c-l h)$ transitions. The band structure is assumed to be parabolic, in which case the gain (which is dependent on the polarization of the light) can be expressed as [5], [6]

$$
\begin{aligned}
g^{(T)}(E)= & \frac{q^{2}}{\pi \epsilon_{0} m_{0}^{2} \hbar c_{0} n_{R} w E} \sum_{\substack{i=c-h h \\
c-l h}} m_{r i} \int_{E_{q i}}^{\infty}\left|M_{i}^{(T)}\right|^{2} \\
& \cdot\left(f_{c}\left(\epsilon_{c i}\right)+f_{v}\left(\epsilon_{v i}\right)-1\right) \frac{h / \tau}{(\epsilon-E)^{2}+(h / \tau)^{2}} d \epsilon
\end{aligned}
$$

where superscript ( $T$ ) denotes the polarization (TE or TM), $i$ denotes one of the transitions $c-h h$ or $c-l h, q$ is the electron charge, $\epsilon_{0}$ the vacuum permittivity, $m_{0}$ the free mass of the electron, $\hbar$ the reduced Planck's constant, $c_{0}$ the speed of light in vacuum, $n_{R}$ the refractive index, $w$ the width of one well, $m_{\mathrm{ri}}$ the relative mass defined as $m_{\mathrm{ri}}=$ $m_{c} m_{v \mathrm{i}} /\left(m_{c}+m_{v \mathrm{i}}\right)$ and $E_{\mathrm{qi}}$ the effective bandgap given by $E_{\mathrm{qi}}=E_{\mathrm{g}}+E_{\mathrm{cl}}+E_{\mathrm{vil}} . E_{\mathrm{cl}}$ and $E_{\mathrm{vil}}$ are the first quantized energies of the conduction band electrons and the valence band holes, respectively. $M_{i}^{(T)}$ is the momentum matrix element between Bloch states in the conduction band and in the valence band. For the $c-h h$ transition the absolute square of the two matrixelements can be expressed as [5] $\left|M_{h}^{(\mathrm{TE})}\right|^{2}=(3 / 4)\left|M_{b}\right|^{2}\left(1+E_{\mathrm{cl}} / \epsilon_{\mathrm{ch}}\right)$ and $\left|M_{h}^{(\mathrm{TM})}\right|^{2}=$ $(3 / 2)\left|M_{b}\right|^{2}\left(1-E_{\mathrm{cl}} / \epsilon_{\mathrm{ch}}\right)$ where $M_{b}$ is the bulk momentum matrix-element between two Bloch states [6]. For the $c-l h$ transitions each matrixelement can be expressed as a sum of the matrixelements for the transitions $c-\ln 1$ and $c-\ln 2$, and can be evaluated as [7] $\left|M_{l}^{(\mathrm{TE})}\right|^{2}=(1 / 4)\left|M_{b}\right|^{2}(5-$ $\left.3 E_{\mathrm{cl}} / \epsilon_{\mathrm{cl}}\right)$ and $\left|M_{l}^{(\mathrm{TM})}\right|^{2}=(1 / 2)\left|M_{b}\right|^{2}\left(1+3 E_{\mathrm{cl}} / \epsilon_{\mathrm{cl}}\right)$. The energies $\epsilon_{\mathrm{ci}}$ are given by $\epsilon_{\mathrm{ci}}=\left(m_{\mathrm{ri}} / m_{c}\right)\left(\epsilon-E_{\mathrm{qi}}\right)+$ $E_{\mathrm{cl}}$. The remaining constants in (2) are the intraband relaxation time $\tau$, the variable of integration $\epsilon$, the Fermi-functions $f_{c}\left(\epsilon_{\mathrm{ci}}\right)$ and $f_{v}\left(\epsilon_{\mathrm{vi}}\right)$ and $\epsilon_{\mathrm{vi}}=\left(m_{\mathrm{ri}} / m_{\mathrm{vi}}\right)\left(\epsilon-E_{\mathrm{qi}}\right)+$ $E_{\mathrm{vil}}$. Equation (2) should normally include a summation over the quantized levels in the well. However, for the InGaAs/InGaAsP system which we are considering, only the first quantized level in the conduction band exists. Thus, the summation is needless as there only is a small probability for transitions between states in the conduction band and valence band with different quantized levels [5]. An expression similar to (2) can be found for $\alpha_{e}(E)$, the only difference being the Fermi-factor which should read $\left(f_{c}\left(\epsilon_{\mathrm{ci}}\right) f_{v}\left(\epsilon_{\mathrm{vi}}\right)\right)$ instead of $\left(f_{c}\left(\epsilon_{\mathrm{ci}}\right)+f_{v}\left(\epsilon_{\mathrm{vi}}\right)-1\right)$.

If we consider only the $c-h h$ transitions, assume that there is no intraband relaxation $(\tau \rightarrow \infty)$ and put $\alpha_{\text {loss }}=0$ $\mathrm{cm}^{-1}$ the noise figure can be expressed as $F_{\text {TWA }}=$ $2\left(f_{c} f_{v}\right) /\left(f_{c}+f_{v}-1\right)$. This expression shows that the smallest noise figure of $3 \mathrm{~dB}$ can be obtained if either $f_{c}=1$ or $f_{v}=1$. This means that a complete inversion $\left(f_{c}=f_{v}=\right.$ 1) is unneccesary for a low noise figure. The reason is that although the gain decreases if the inversion is not complete, so does the spontaneous emission, leaving the noise figure unchanged. The equation also explains the reason for the low noise figure in a QW SOA: because of the staircase-like density of states for the electrons and holes in quantum-well structures and the small effective mass of the electrons in the conduction band, the Fermi-function for the electrons in the conduction band approaches unity rapidly with increasing current, leading to a low noise figure.

\section{Measurements and Discussion}

The measurements are carried out on an InGaAs/InGaAsP DCPBH (double-channel planar buried-heterostructure) MQW device, with a bandstructure (conduction and valence band extrema) as shown in Fig. 1. The active region consists of four $80 \AA$ wide InGaAs quantum-wells separated by $130 \AA$ thick InGaAsP barrier layers, lattice matched to InP. The total confinement factor (four wells) is $5 \%$. The length of the cavity is $800 \mu \mathrm{m}$; the facets have been antireflection coated, resulting in an average reflectivity of $3 \cdot 10^{-3}$.

The measured values of the single-pass gain, for both TEand TM-polarized light are shown in Fig. 2, at an injection current of $225 \mathrm{~mA}$. The single-pass gain for TE-polarized light reaches a maximum of $22 \mathrm{~dB}$ at a wavelength of 1535 $\mathrm{nm}$. The $1 \mathrm{~dB}$ bandwidth of the single-pass gain is in excess of $60 \mathrm{~nm}$. At $1535 \mathrm{~nm}$ the gain for the TM-mode is approximately $6 \mathrm{~dB}$ lower than for the TE-polarization. The low gain for the TM-polarization is a drawback for the QW SOA, but can be remedied by incorporating strain into the QW-structure [8].

The TWA noise figure can be estimated experimentally by using the formula (which is analogous to (41) in [9]):

$$
F_{\mathrm{TWA}}=2 \frac{P_{\text {meas }}}{\eta} \frac{\lambda^{3}}{h c_{0}^{2} \Delta \lambda} \frac{1-R G_{s}}{(1-R)\left(G_{s}-1\right)}
$$

where $P_{\text {meas }}$ is the measured power of the spontaneous emission for one polarization in a given optical filter bandwidth $\Delta \lambda, \eta$ the total coupling efficiency from the amplifier into the optical power meter, $\lambda$ the wavelength in vacuum, $h$ Planck's constant, $R$ the modal reflectivity at the appropriate wavelength and $G_{s}$ the single-pass gain. In (3) it is assumed that the filter bandwidth is several times larger than the mode-spacing in the SOA. (In the measurements a filter bandwidth of $1 \mathrm{~nm}$ is used, while the mode-spacing is 0.4 nm.) It should be noted that the total noise figure for a resonant amplifier is given by $F=\eta_{i}^{-1} X F_{\text {TwA }}$ where $\eta_{i}$ is the coupling efficiency and $X$ is the excess noise coefficient given by [10] $X=\left(1+R G_{s}\right)\left(G_{s}-1\right) /(1-R) / G_{s}$. Fig. 3 shows the measured values of the TWA noise figure for the TE-mode as a function of the wavelength at an injection current of $225 \mathrm{~mA}$. The noise figure varies from $5.1 \mathrm{~dB}$ at $1500 \mathrm{~nm}$ to $3.9 \mathrm{~dB}$ at $1550 \mathrm{~nm}$, indicating a dependence on the wavelength. The uncertainty on the noise figure is estimated to be $0.6 \mathrm{~dB}$. The lowest TWA noise figure of $3.9 \mathrm{~dB}$ compares well with a previously reported total noise figure of $4.6 \mathrm{~dB}$ [1] considering their excess noise of $X=0.7 \mathrm{~dB}$. For comparison, a typical noise figure for a bulk TWA of 5.2 $\mathrm{dB}[10]$ has previously been reported. 

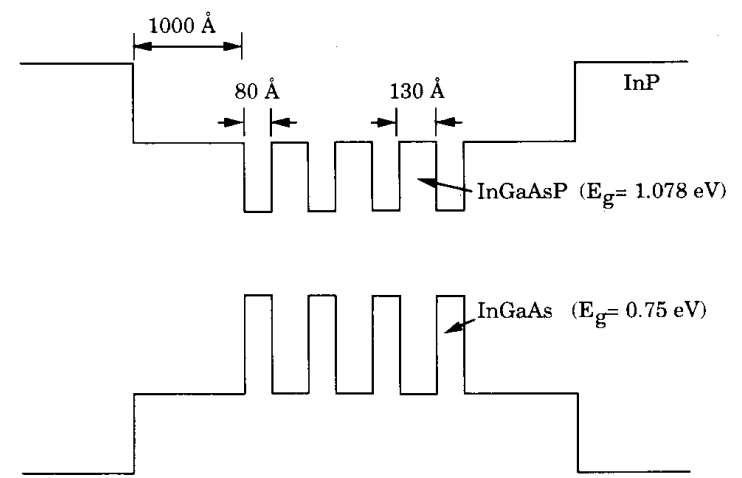

Fig. 1. Energy band diagram (extrema) for the device used in the measure ments.

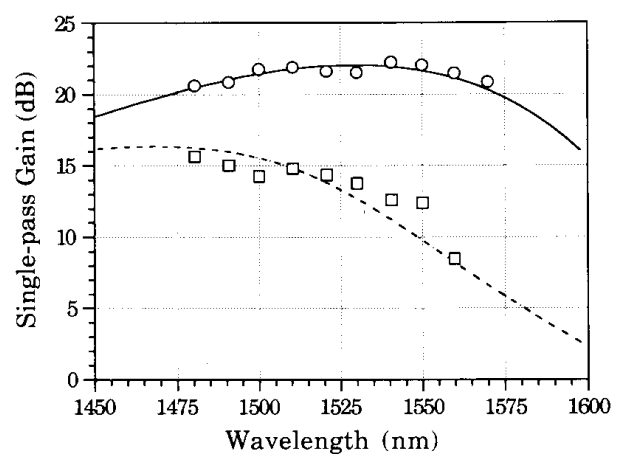

Fig. 2. Measured and calculated results for the single-pass gain versus wavelength at an injection current of $225 \mathrm{~mA}(\mathrm{TE}=0, \square$; $\mathrm{TM}=\square, \cdots$ ).

The calculations are performed using the following parameters: $m_{c}=0.041 m_{0}$ for InGaAs (wells), $m_{c}=0.064 m_{0}$ for InGaAsP (barriers), $m_{\mathrm{vh}}=0.44 m_{0}$ and $m_{\mathrm{vh}}=0.055$ $m_{0}$ for both wells and barriers, $E_{g}=0.75 \mathrm{eV}$ for InGaAs, $E_{g}=1.078 \mathrm{eV}$ for InGaAsP and $\left|M_{b}\right|^{2}=4.7 \cdot 10^{-49} \mathrm{Jkg}$. The depth of the conduction band well has been assumed to be $40 \%$ of the difference between the bandgaps of InGaAs and InGaAsP. For the internal losses the values $\alpha_{a}=215$ $\mathrm{cm}^{-1}$ for the active layer and $\alpha_{b}=5 \mathrm{~cm}^{-1}$ for the barrier and cladding layers have been used. The bandgap shrinkage due to thermal effects and the presence of free carriers [11] has been taken into account. The Fermi-energies are found from the usual rate-equation for the carriers [12]. An intraband relaxation time of $\tau=2.5 \cdot 10^{-14} \mathrm{~s}$ gives a curvature of the gain spectrum that agrees well with the measurements.

The calculated curves for the single-pass gain for the TEand the TM-polarization (as indicated in Fig. 2 by the solid and dashed line, respectively) are in good agreement with the experimental results. It is apparent that the gain peak is reached at different wavelengths for the two polarizations. This is due to the fact that the matrix-elements are different for the TE- and the TM-polarization. The calculated noise figure agrees reasonably with the experimental values. However, the wavelength dependence is not reproduced very well. A possible explanation is a wavelength dependency of

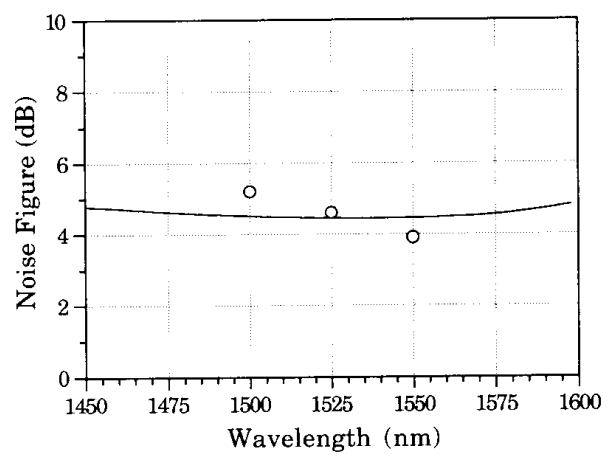

Fig. 3. Measured $(O)$ and calculated $(-)$ results for the TWA noise figure (TE-mode) versus wavelength at an injection current of $225 \mathrm{~mA}$.

the internal loss [13]. It is worth noting that the noise figure for a QW SOA is flat over a considerably larger bandwidth than for a bulk SOA [14]; this can be attributed to the staircase-like density of states in a QW. For completeness it should be mentioned that the calculated carrier density is $5.4 \cdot 10^{18} \mathrm{~cm}^{-3}$. The inversion is estimated to have a value of approximately $\gamma_{\mathrm{sp}}=1.12$ at the gain peak, which is quite close to the minimum value for the inversion of 1 .

\section{CONCLUSION}

The wavelength dependence of the noise figure and the single-pass gain for an InGaAs/InGaAsP MQW SOA has been theoretically predicted and is in reasonable agreement with the experimental results. The bandwidth of both the noise figure and the single-pass gain is bigger for a QW SOA than for a bulk SOA. Neglecting the excess noise due to facet reflections, the measured noise figure is $3.9 \mathrm{~dB}$ at $1550 \mathrm{~nm}$, increasing to $5.1 \mathrm{~dB}$ at $1500 \mathrm{~nm}$, which confirms the low noise properties of QW SOA's.

\section{REFERENCES}

[1] T. Saitoh, Y. Suzuki, and H. Tanaka, "Low noise characteristics of a GaAs-AIGaAs multiple-quantum-well semiconductor laser amplifier," IEEE Photon. Technol. Lett., vol. 2, pp. 794-796, Nov. 1990.

[2] G. Eisenstein, U. Koren, G. Raybon, T. L. Koch, J. M. Weisenfeld, M. Wegener, R. S. Tucker, and B. I. Miller, "Large and small signal gain characteristics of $1.5 \mu \mathrm{m}$ multiple quantum well optical amplifiers," Appl. Phys. Lett., vol. 56, pp. 1201-1203, Mar. 1990.

[3] K. Komori, S. Arai, and Y. Suematsu, "Noise in semiconductor laser amplifiers with quantum box structure," IEEE Photon. Technol. Lett., vol. 3, pp. 39-41, Jan. 1991.

[4] E. O. Kane, "Band structure of indium antimonide," J. Phys. Chem. Solids, vol. 1, pp. 249-261, 1957.

[5] M. Asada, A. Kameyama, and Y. Suematsu, "Gain and intervalence band absorption in quantum-well lasers," IEEE J. Quantum Electron., vol. QE-20, pp. 745-753, July 1984.

[6] R. H. Yan, S. W. Corzine, L. A. Coldren, and I. Suemune, "Corrections to the expression for gain in GaAs," IEEE J. Quantum Electron., vol. QE-26, pp. 213-216, Feb. 1990.

[7] M. Yamada, S. Ogita, M. Yamagishi, and K. Tabata, "Anisotropy and broadening of optical gain in a GaAs/AlGaAs multiquantum-well laser," IEEE J. Quantum Electron., vol. QE-21, pp. 640-645, June 1985.

[8] T. C. Chong, and C. Fonstad, "Theoretical Gain of Strained-Layer Semiconductor Lasers in the Large Strain Regime," IEEE J. Ouantum Electron., vol. QE-25, pp. 171-178, Feb. 1989.

[9] Y. Yamamoto, "Noise and error rate performance of semiconductor laser amplifiers in PCM-IM optical transmission systems," IEEE J. Quantum Electron., vol. QE-16, pp. 1073-1081, Oct. 1980.

[10] T. Saitoh and T. Mukai, " $1.5 \mu$ m GalnAsP travelling-wave semicon- 
ductor laser amplifier," IEEE J. Quantum Electron., vol. QE-23, pp. 1010-1020, June 1987.

[11] D. A. Kleinman and R. C. Miller, "Band-gap renormalization in semiconductor quantum wells containing carriers,"' Phys. Rev. B, vol. 32, pp. 2266-2272, Aug. 15, 1985.

[12] M J Adams, J. V Collins, and I. D. Henning, "Analysis of semiconductor laser optical amplifiers," IEE Proc., vol. 132, pt. J., pp. 58-63, Feb. 1985.
[13] M. G. Oberg, and N. A. Olsson, "Wavelength dependence of noise figure of a travelling-wave GaInAsP/InP laser amplifier," Electron. Lett., vol, 24, pp. 99-100, Jan. 21, 1989.

[14] B. Mikkelsen, D. S. Olesen, K. E. Stubkjaer, Z. Wang, A. J. Collar, and G. D. Henshall, "Temperature-Dependent Gain and noise of 1.5 $\mu \mathrm{m}$ Laser Amplifiers," Electron. Lett., vol. 25, pp. 357-359, Mar. 2,1989

\title{
+21 dBm Erbium Power Amplifier Pumped by a Diode-Pumped Nd:YAG Laser
}

\author{
S. G. Grubb, W. F. Humer, R. S. Cannon, T. H. Windhorn, S. W. Vendetta, K. L. Sweeney,
} P. A. Leilabady, W. L. Barnes, K. P. Jedrzejewski, and J. E. Townsend

\begin{abstract}
Efficient energy transfer has been demonstrated in an $\mathrm{Er} / \mathrm{Yb}$ co-doped phosphorus doped silica fiber for the first time. This has indirectly allowed the use of reliable, high-power AlGaAs diode laser arrays as the semiconductor pump source through the use of a diode-pumped Nd:YAG (DPL) laser operating at $1064 \mathrm{~nm}$. Small signal gains of $42 \mathrm{~dB}$ and output powers of $71 \mathrm{~mW}(+18.5 \mathrm{dBm})$ have been observed with a single DPL. Bidirectional pumping with two DPL's has yielded an output power of $130 \mathrm{~mW}(+21 \mathrm{dBm})$.
\end{abstract}

\section{INTRODUCTION}

$\mathbf{M}$ $\mathrm{UCH}$ of the recent discussion regarding the systems deployment of the erbium optical amplifier has focussed on the pump source. 980 and $1480 \mathrm{~nm}$ pump sources are the most widely considered options and each have advantages and disadvantages with regards to efficiency, intrinsic noise figure, pump laser power and lifetime. Co-doped fibers are an attractive means of alleviating constraints on the pump source wavelength by using a sensitizer with a broad absorption band. $\mathrm{Yb}$ is especially attractive in this regards as it exhibits an intense broad absorption between 800 and 1080 $\mathrm{nm}$, spanning several convenient pump wavelength source options. An efficient amplifier using an $\mathrm{Er}^{3+} / \mathrm{Yb}^{3+}$ co-doped phosphate glass fiber has previously been demonstrated [1]. However, these fibers suffer several drawbacks, including poor mechanical strength, higher intrinsic loss, as well as a thermal and index mismatch when compared to silica fibers.

Manuscript received January 2, 1992.

S. G. Grubb, W. F. Humer, R. S. Cannon, T. H. Windhorn, and S. W Vendetta are with Amoco Technology Company, Naperville, IL 60566.

K. L. Sweeney and P. A. Leilabady are with Amoco Laser Company, Naperville, IL 60566.

W. L. Barnes, K. P. Jedrzejewski, and J. E. Townsend are with the Optoelectronics Research Centre, University of Southampton, Southampton, UK S09 5NH.

IEEE Log Number 9200305 .
Previous experiments with $\mathrm{Er} / \mathrm{Yb}$ co-doped silica fibers showed inefficient energy transfer [2]. The limiting factor was the relatively long lifetime of the ${ }^{4} \mathrm{I}_{11 / 2}$ band of $\mathrm{Er}$, around $3 \mu \mathrm{s}$ in silica. This allows significant back-transfer to $\mathrm{Yb}^{3+}$ with a corresponding loss of inversion. The $\mathrm{Yb}^{3+}$ to $\mathrm{Er}^{3+}$ energy transfer efficiency is extremely host dependent, with a high phonon energy host being preferred to decrease the intermediate ${ }^{4} I_{11 / 2}$ level lifetime of erbium [3]. For example, we have measured an initial energy transfer efficiency (approaching zero erbium inversion) of only $5 \%$ in an $\mathrm{Er} / \mathrm{Yb}$ germanosilica fiber while the initial transfer efficiency is $90 \%$ in a phosphate glass host. We have found that small amounts of phosphorus, when added to silica-based fibers, mimics the spectroscopic environment of the phosphate glass host. Such fibers exhibit greatly improved properties relative to the previously fabricated phosphate glass fibers.

We have chosen to pump on the long-wavelength tail of the $\mathrm{Yb}^{3+}$ absorption using a diode-pumped Nd:YAG laser (DPL) operating at $1064 \mathrm{~nm}$. The advantages of the DPL are the use of mature, efficient and high-power AlGaAs diode lasers, the high beam quality and the scalability of this approach with pump array size. Besides the obvious frequency conversion, the DPL is also a brightness converter, allowing up to several hundred milliwatts to be coupled from a single pump source into single-mode fiber. Unlike direct diode excitation, this approach is directly scalable with nondiffraction limited pump array size. Ultrahigh power amplifiers with output powers have been demonstrated in $1.48-\mu \mathrm{m}$-pumped erbium amplifiers. These amplifiers, however, require four separate pump sources multiplexed with polarization preserving fiber and bulk beamsplitting cubes. Besides the insertion losses of these devices, they are liable to introduce significant reflections in this high gain amplifier system, both contributing to a degraded noise performance. 